\title{
Joint China-US Call for Employing a Transdisciplinary Approach to Emerging Infectious Diseases
}

\author{
Jonna A. K. Mazet, ${ }^{1}$ Qin Wei, ${ }^{2}$ Guoping Zhao, ${ }^{3}$ Derek A. T. Cummings, ${ }^{4}$ \\ James Stephen Desmond, ${ }^{5}$ Joshua Rosenthal, ${ }^{6}$ Charles H. King, ${ }^{7}$ Wuchun Cao, ${ }^{8}$ \\ Aleksei A. Chmura, ${ }^{5}$ Emily A. Hagan, ${ }^{5}$ Shuyi Zhang, ${ }^{9}$ Xiangming Xiao, ${ }^{10}$ \\ Jianguo $\mathrm{Xu},{ }^{11}$ Zhengli Shi, ${ }^{12}$ Feng Feng, ${ }^{2}$ Xiuping Liu, ${ }^{2}$ Weiqing Pan,${ }^{13}$ \\ Guangjian Zhu, ${ }^{5}$ Liyao Zuo, ${ }^{2}$ and Peter Daszak ${ }^{5}$ \\ ${ }^{1}$ One Health Institute, University of California, Davis' School of Veterinary Medicine, Davis \\ ${ }^{2}$ National Natural Science Foundation of China, Beijing, China \\ ${ }^{3}$ Shanghai Institutes for Biological Sciences, Shanghai, China \\ ${ }^{4} J o h n s$ Hopkins Bloomberg School of Public Health, Baltimore \\ ${ }^{5}$ EcoHealth Alliance, New York \\ ${ }^{6}$ Division of Epidemiology and Population Studies, Fogarty International Center, National Institutes of Health, New York \\ ${ }^{7}$ Case Western Reserve University, Cleveland \\ ${ }^{8}$ Academy of Military Medical Sciences, Beijing, China \\ ${ }^{9}$ East China Normal University, Shanghai, China \\ ${ }^{10}$ University of Oklahoma, Norman \\ ${ }^{11}$ National Institute for Communicable Disease Control and Prevention, Beijing, China \\ ${ }^{12}$ Wuhan Institute of Virology, Chinese Academy of Sciences, Wuhan, China \\ ${ }^{13}$ Second Military Medical University, Shanghai, China
}

In the spring of 2013, a newly pathogenic H7N9 influenza virus emerged in people in China, likely associated with wild and domestic birds (Kageyama et al. 2013). Marking the exact scenario that public health experts had fearedpeople were being infected, getting sick, and dying without the source of the virus being rapidly and definitively identified. In the absence of a clear understanding of the mode of transmission, early control of this epidemic proved difficult, especially since the most likely suspect reservoirs, animals being sold in markets, were not exhibiting the signs of illness that would help officials target

Recommendations are the result of Collaborative Workshop on the Ecology and Evolution of Infectious Disease sponsored by both the US and China's National Science Foundations in Kunming, China, October 2012. Apart from Emily A. Hagan all authors were in attendance and participated in the workshop.

Published online: December 8, 2015

Correspondence to: Jonna A. K. Mazet, e-mail: jkmazet@ucdavis.edu mitigation measures and help citizens avoid exposure. Strict safety measures were enacted, including closures of markets that sell live birds and culling of animals in areas where patients have been diagnosed with confirmed cases. The associated costs of control and treatment of the sick, including secondary loss of poultry, were increased because interventions could not be efficiently targeted at the source of infection or the drivers of the virus' emergence from that source.

Scientific and official responses to H7N9 influenza highlight the significant advances in infectious disease management in China and around the world. WHO's global influenza surveillance network and the International Health Regulations requirements for rapid reporting have greatly increased the candidness of reporting; today there is also a greater openness of global scientific collaboration due to the previous experiences with the SARS and $\mathrm{H} 5 \mathrm{~N} 1$ 
epidemics. For example, genetic sequences of H7N9 virus isolates were made publically available within days of its identification, enabling teams around the world to study the virus and immediately advancing our ability to control the disease, unlike some cases of earlier decades (Osterholm and Kelley 2012). The virus itself was also rapidly detected as a result of the vigilance in influenza surveillance. Reagents and protocols for rapid diagnosis and increased surveillance were made available through the local and international efforts, the fruit of the immense investment of many countries within this area of scientific research. H7N9 provides one example that highlights the scientific advances of recent decades and the bolstering of international collaboration when needed, yet human infection with this strain of influenza remains a problem in 2015 as we struggle to get another yet another devastating zoonotic disease, the Ebola epidemic in West Africa, under control. Unfortunately, despite intensive, high-quality research efforts by a talented cadre of scientists globally, we are still not able to predict which viruses, including specific influenza subtypes, will become pathogenic to people; which will cause new epidemics in animals; nor where and under what circumstances disease will emerge. The challenge for the global health community remains: efficient targeting of investment in science, prevention, surveillance, and preparedness for infectious diseases before or immediately upon emergence.

To further address this challenge, the National Science Foundations of both China and the United States convened a small working group of infectious disease experts with experience in the ecology of microbial pathogens and disease emergence, including Severe Acute Respiratory Syndrome (SARS), influenza, and a number of other diseases. In addition to the sponsors, the Chinese Academy of Sciences, academia in both countries, private research institutes, China Centers for Disease Control, and US National Institutes of Health were represented. The necessity of expanding collaborative, interdisciplinary work was clear. Therefore, the two countries decided to put forth this international call for multisectoral engagement that could transcend the high-quality, but largely scientifically siloed, approach to infectious diseases that has been occurring globally. China and the US have much in common and much to gain from increased collaboration in this realm, as well as the need and ability to lead the call for such a transdisciplinary global approach to EID research, surveillance, and management. This call is not altogether altruistically motivated, however, as the two are among the countries harboring the most documented influenza diversity in the world (Rejmanek et al. 2015). In addition, both countries are leading global economies; have highly mobile populations that travel extensively for commerce and tourism; face internal disparities in access to healthcare; have had recent experiences with pandemic response; are facing a rapid growth in resources consumption; have major investments in pioneering technological advances and large scientific communities; and are investing heavily in emerging disease investigation and science.

As evidence of commitment to respond to their own call, scientists from China and the US have been publishing together at increasing rates in the last decade. The US is the second largest producer of scientific articles (26\%), and China is the third (11\%), with the most growth of a developing country (up from $3 \%$ in 2001 to $11 \%$ in 2011) (Board 2014). In publications primarily authored in the US, Chinese scientists are currently the most frequent international partnering coauthors (16\%)-an exceptional rise from just 5\% in 2002 (Board 2014). Academically, the two countries are increasingly linked, with the number of Chinese graduate students in the US in science and engineering programs growing from 15,000 to 43,000 (19872010); in 2007 alone, 4,300 doctoral degrees were awarded to Chinese nationals from universities in the US (Xie et al. 2014). Spending on research in these two countries also demonstrates the ability and desire to further scientific knowledge and focused collaboration. In 2012, the US spent 2.8\% GDP ( $\$ 447$ billion) on research, that same year China was not far behind, spending 1.8\% GDP (\$164 billion), up from $0.7 \%$ in 1991 and with projections for impressive monetary commitments to the advancement of science (Xie et al. 2014). Evidenced by these investments, both US and China have pledged to advance research and have shown impressive growth in international collaborations; thus, it is critical that they continue to set an example for transdisciplinary, global collaboration in a directed and focused manner-achieving what neither could do without the other, while promoting similar efforts across the scientific community.

Active economies with domestic agricultural intensification, like the US and China, are especially challenged by EIDs, as their continued growth and development facilitates new and dynamic ecological circumstances in which potential pathogens can readily emerge or evolve (Collins 2001). In both countries, vast areas have been deforested for lumber production and to clear land for other uses, including agriculture and urbanization. This type of habitat 
change results in a rapid and dramatic loss of biodiversity and may facilitate the increase in numbers of just a few adaptable species of plants and animals (Foley et al. 2005). It also increases the likelihood of people coming into contact with those species, as well as changing the ways in which they encounter each other (Murray and Daszak 2013). This process has been recognized as means to alter the ecological balance between pathogens and their hosts and has provided access to new hosts for pathogen spillover (Keesing et al. 2006).

Despite the need for such environmental modification to support growing populations and economies, the maintenance of biological diversity is increasingly demanded by the citizens of both developed and developing countries, who recognize the numerous services and benefits to quality of life that are provided through such diversity—including increasing productivity of agricultural land, resilience against adverse natural and anthropogenic events, increased capacity to provide fuel and fiber, benefits to people's welfare, and in many cases direct improvements to health outcomes (Patz et al. 2004). Therefore, in China and the US, many degraded ecosystems are being rapidly altered for a second time, in a greening effort, to remediate previous environmental damage and protect or repair loss of biodiversity. These efforts are important for many reasons. However, as habitat recovery is most often primarily designed for vertebrate suitability, very little attention is paid to the considerations of microbial colonization or potential overgrowth of invertebrate vectors that can contribute to the transmission and spread of diseases.

For example, echinococcosis, one of the most important parasitic helminth diseases of poor people worldwide, may be re-emerging in areas of Northwest China after a cycle of 30 years of land clearing and agricultural intensification. This increase may be associated with a recent ban on sheep grazing to help remediate soil erosion and the near-complete loss of natural vegetation (Yang et al. 2012). The recent environmental efforts also include bans on rodenticides, allowing the re-colonization of rodent intermediate hosts and their predators that serve as definitive hosts of the parasite. The resulting "recovering" environment is therefore also conducive for increased transmission of the pathogen to hosts, including humans; an unintended consequence of greening this agriculturally intensified area. Similar examples of increased pathogen prevalence and disease transmission with land use and host diversity changes have been documented, especially for malaria (Patz et al. 2004) and Lyme disease (Levi et al. 2012). These situations illustrate that we must take care to use a holistic or One Health approach to environmental conversion for both increased economic development and restorationthat we must remember that the health of people, animals, and the environment are inextricably linked. In addition, we must track and address the unintended influence on disease transmission and pathogen ecology of both economic development and environmental improvements.

The coauthors met in China to discuss the ecology and evolution of infectious disease and the steps that must be considered as priorities to promote the health of the planet. As a result of the increase in successful scientific collaboration, the working group agreed that China and the US are well positioned to lead a call for ambitious and scientifically sophisticated program of work that yields relevant, highquality science, and sets examples for best practices around the world, through a collaborative and open communication framework.

A general consensus was reached among experts at the workshop that, although some aspects of infectious disease transmission and emergence are being productively addressed by the current global health community, increasingly collaborative, transdisciplinary attention is needed for the development of a detailed understanding of the drivers of disease emergence (Jones et al. 2008) and their implications and associated recommendations for infectious disease control. Those drivers identified by the group of most immediate need for increased effort were

\section{- Landscape Change}

As illustrated above, both agricultural and landscape intensification and remediation can have unintended disease consequences. Serious health consequences also result from impaired water safety and security due to water impoundment for irrigated agriculture, hydroelectricity generation, and shared sources for consumption by both animals and humans. Similarly, urbanization and downstream greening create new environments for pathogen transmission and evolution, often in situations with high concentrations of susceptible populations ( $\mathrm{Li}$ et al. 2012).

\section{- Migration, Transportation, and Trade}

Risk are heightened as rural to urban migration brings a constant stream of new organisms to human- and pestintensified areas. International migration for employment opportunities may also bring the urban poor into circumstances ripe for pathogen transmission (Liu et al. 2013). Increasing trade and novel business ventures have 
led some looking for employment to cross country borders, exposing them to biological, social, and healthcare environments that are unfamiliar and greatly increasing susceptible workers' chances of acquiring new infections through contact with wildlife, domestic animals, food, or human sources of diseases. As they are returning home, to a population naïve to the pathogen, there are increased opportunities that could facilitate virus transmission or even trigger the beginning of the next pandemic.

\section{- Economic Development and Food Preferences}

As economies improve, the demand for animal-based protein increases (Bellaver and Bellaver 1999). This demand facilitates livestock market chains from rural to urban areas, as well as increases the transport of wildlife and their flora to cities. As people become more affluent, their desire for traditional foods rarely decreases; instead there is an increase in their ability to purchase these items at higher prices and frequency. The resulting growing wildlife market chain is also often clandestine, and therefore suffers from poor biosecurity. The best recent example of disease emergence from the rural to urban wildlife market chain comes from the SARS pandemic, which not only resulted in loss of life, but had a devastating effect on the Chinese and Hong Kong economies (Keogh-Brown and Smith 2008).

\section{- Climate Variability and Change}

The potential increase in range and spread of pathogens with climatic change and variation must be better examined. Recent examples of pathogens emerging in new areas of the globe, driven by changes in wildlife host migration patterns, illustrate that environmental drivers of pathogen spread need to be included in the holistic development of disease mitigation interventions (Altizer et al. 2013; Goldstein et al. 2009). Finally, land degradation and rural poverty combined with changes in water availability from climate variability are driving migration (Sjogersten et al. 2013); these factors combined are influencing pathogen dynamics and must be considered for increased intellectual and financial investment in order to predict and prevent disease emergence and protect local and global health.

Research disciplines inherently work according to long-standing cultures, and their historical development is reflected in the fruit of their collaborations. For example, $56 \%$ of astronomy articles have international representation among coauthors, while chemistry, social sciences, and other life sciences stand at only $17-21 \%$. Thus, some fields need a concerted effort to encourage international collaboration (Board 2014). In addition, group efforts involving multiple disciplines facilitate outcomes that transcend what can be accomplished in isolation and are increasingly needed to approach complex global health problems. We, therefore, issue a call for the US and China to lead efforts to improve the global environment for collaborative, transdisciplinary infectious disease research using a One Health approach. To successfully achieve useful outcomes, we need to have substantial advances in three areas: (1) transdisciplinary research with a One Health focus, most crucially the fields of micro and molecular biology, medicine, veterinary medicine, epidemiology, ecology, economics, engineering, genetics, mathematics, policy, systems analysis, and agricultural and environmental sciences; (2) integration of technology for data collection, analysis, and communication, including information technology and geospatial technologies; and (3) broader participation of scientists and motivated citizens for data collection and evaluation, individual-based decision making, and human behavioral change. We hope to see collaboration among all relevant disciplines to holistically assess the drivers of infectious disease emergence that are key to global health and economic security. The World Bank estimates that economic losses from fatal animal-origin infectious diseases between 1997 and 2009 totaled at least US\$80 billion and that, had a severe influenza pandemic emerged, the costs could have approached US\$3 trillion. Costs for the 2015 West Africa Ebola epidemic are still rising and estimated to reach more than $\$ 32$ billion for just the one outbreak (World Bank). Further, they estimate that, in addition to millions of lives, $\$ 6.7$ billion per year could be saved globally by preventing emerging disease outbreaks (Bank 2012). To be most efficient and successful, a joint China-US led effort should focus on socio-ecological systems changes facilitating and forcing pathogen evolution and emergence, rather than on specific infectious agents or geopolitical regions. Significant multi-lateral investment in pathogen discovery and characterization, agent-host dynamics, multi-organismal diagnostic technologies, and mathematical forecasting for risk identification and disease prevention and control are specifically encouraged.

In addition to Ebola, since 2013 the world has seen MERS (Middle Eastern Respiratory Syndrome) spillover into the human population and increasing and spreading cases of HPAI H5N2 in birds globally. H7N9 illustrated the necessity 
of international cooperation and collaboration for the global community, especially in light of the successful timely responses, yet these were reactive, not the encouraged proactive approach that the world is still missing. These leading nations have the opportunity to set an example for best practices in science by combining intellectual, technological, and financial resources to help reduce the impacts from emerging infectious diseases at every level, from families to global economies. Working more closely together, the world can head off the threat of pandemics through an improved understanding of the underlying drivers of disease emergence, with benefits for science, health, ecological integrity, and economic well-being.

\section{ACKNOWLEDGMENTS}

This material is based upon work supported by the US National Science Foundation Grant No. DEB-1257513 and made possible by the generous support of American people through the United States Agency for International Development (USAID) Emerging Pandemic Threats program, PREDICT project.

\section{REFERENCES}

Altizer S., Ostfeld RS, Johnson PT, Kutz S, Harvell CD (2013) Climate change and infectious diseases: from evidence to a predictive framework. Science 341(6145):514-519 (DOI: 10. 1126/science.1239401)

World Bank (2012) People, Pathogens and Our Planet: The Economics of One Health People, Pathogens and Our Planet, Washington, DC, pp 1-65

Bellaver C, Bellaver IH (1999) Livestock production and quality of societies' life in transition economies. Livestock Production Science 59(2-3):125-135 (DOI: 10.1016/s0301-6226(99)00021-4)

National Science Board (2014) Science and Engineering Indicators 2014. Arlington VA: National Science Foundation

Collins AE (2001) Health ecology, land degradation and development. Land Degradation \& Development 12(3):237-250 (DOI: 10.1002/ldr.436)

Foley JA, DeFries R, Asner GP, Barford C, Bonan G, Carpenter SR, et al. (2005) Global consequences of land use. Science 309(5734):570-574 (DOI: 10.1126/science.1111772)

Goldstein T, Mazet JAK, Gill VA, Doroff AM, Burek KA, Hammond JA (2009) Phocine distemper virus in northern sea otters in the Pacific Ocean, Alaska, USA. Emerging Infectious Disease 15(6):925-927 (DOI: 10.3201/eid1506.090056)
Jones KE, Patel NG, Levy MA, Storeygard A, Balk D, Gittleman JL, Daszak P (2008) Global trends in emerging infectious diseases. Nature 451(7181):990-993 (DOI: 10.1038/nature06536)

Kageyama T, Fujisaki S, Takashita E, Xu H, Yamada S, Uchida Y, et al. (2013) Genetic analysis of novel avian A(H7N9) influenza viruses isolated from patients in China, February to April 2013. Eurosurveillance 18(15):7-21

Keesing F, Holt RD, Ostfeld RS (2006) Effects of species diversity on disease risk. Ecology Letters 9(4):485-498 (DOI: 10.1111/j. 1461-0248.2006.00885.x)

Keogh-Brown MR, Smith RD (2008) The economic impact of SARS: how does the reality match the predictions? Health Policy 88(1):110-120 (DOI: 10.1016/j.healthpol.2008.03.003)

Levi T, Kilpatrick AM, Mangel M, Wilmers CC (2012) Deer, predators, and the emergence of Lyme disease. Proceedings of National Academy of Sciences USA 109(27):10942-10947 (DOI: 10.1073/pnas.1204536109)

Li X-H, Liu J-L, Gibson V, Zhu Y-G (2012) Urban sustainability and human health in China, East Asia and Southeast Asia. Current Opinion in Environmental Sustainability 4(4):436-442 (DOI: 10.1016/j.cosust.2012.09.007)

Liu S, Hu CXJ, Mak S (2013) Comparison of health status and health care services utilization between migrants and natives of the same ethnic origin: the case of Hong Kong. International Journal of Environmental Research and Public Health 10(2):606622 (DOI: 10.3390/ijerph10020606)

Murray KA, Daszak P (2013) Human ecology in pathogenic landscapes: two hypotheses on how land use change drives viral emergence. Current Opinion Virology 3(1):79-83 (DOI: 10.1016/ j.coviro.2013.01.006)

Osterholm MT, Kelley NS (2012) Mammalian-transmissible H5N1 influenza: facts and perspective. Mbio 3(2) (DOI: 10. 1128/mBio.00045-12)

Patz JA, Daszak P, Tabor GM, Aguirre AA, Pearl M, Epstein J, Working Group on Land Use Change and Disease Emergence, et al. (2004) Unhealthy landscapes: policy recommendations on land use change and infectious disease emergence. Environmental Health Perspective 112(10):1092-1098 (DOI: 10.1289/ ehp.6877)

Rejmanek D, Hosseini PR, Mazet JAK, Daszak P, Goldstein T (2015) Evolutionary dynamics and global diversity of influenza A virus. Journal of Virology (DOI: 10.1128/JVI.01573-15)

Sjogersten S, Atkin C, Clarke ML, Mooney SJ, Wu B, West HM (2013) Responses to climate change and farming policies by rural communities in northern China: a report on field observation and farmers' perception in dryland north Shaanxi and Ningxia. Land Use Policy 32:125-133 (DOI: 10.1016/j.land usepol.2012.09.014)

Xie Y, Zhang C, Lai Q (2014) China's rise as a major contributor to science and technology. Proceedings of National Academy of Sciences USA 111(26):9437-9442 (DOI: 10.1073/pnas. 1407709111)

Yang YR, Clements ACA, Gray DJ, Atkinson JAM, Williams GM, Barnes TS, McManus DP (2012) Impact of anthropogenic and natural environmental changes on Echinococcus transmission in Ningxia Hui Autonomous Region, the People's Republic of China. Parasit Vectors 5 (DOI: 10.1186/1756-3305-5-146) 